Acute medicine

\section{Acute medicine: past, present, and future}

\section{J R Dowdle}

\section{Developments in specialist acute care should lead to better quality of care for patients.}

"O ver the past few years there has been a growing realisation that there is a need for a senior medical presence in Medical Assessment and Admission units (MAUs). This has been manifest by the large number of appointments that have been made to MAUs at Consultant and other levels". ${ }^{1}$ A significant point in the development of acute medicine was marked on 3 July 2003. It was the day when the Specialist Training Authority recognised acute medicine as a subspecialty of general (internal) medicine $(\mathrm{G}(\mathrm{I}) \mathrm{M})$ and subsequently trainees have been appointed to specialist registrar programmes for higher training in both $\mathrm{G}(\mathrm{I}) \mathrm{M}$ and acute medicine. The development of acute medicine however has a much longer history.

There was a time when all physicians were expected to be competent in both the immediate and subsequent management of all common medical disorders, and thus were general physicians. However, fascination with the disorders of particular organ systems resulted in many clinicians developing more specific expertise and becoming "specialists". Formalisation of medical training in the 1970s defined specialty training, and facilitated the development of the physician with special interest in a particular specialty. With specialisation came the development of specialist societies and many physicians became more committed to their specialties than to the generalities of the acute intake. The creation of specialties within medicine should have raised concerns about the ability of specialists in one specialty to deliver the best care to patients suffering from the acute disorders of another specialty, but as the physicians involved in the acute intake practised general medicine as well as their specialty, it was assumed that acute medical care in all situations could still be delivered by all physicians. Acute medicine thus remained part of G(I)M and the Royal Colleges have always emphasised the importance of $\mathrm{G}(\mathrm{I}) \mathrm{M}$ in this regard. Gradually it became evident that specialist care of acute medical conditions yielded better outcomes than did nonspecialist care, ${ }^{2}$ but the organisation of healthcare provision in the UK made it virtually impossible to provide parallel specialist intakes in all fields of medicine, even in the largest hospitals, and thus most patients admitted acutely continue to come under the care of consultants not necessarily specialising in their presenting conditions.

Furthermore, the concept of the physician as "consultant" has meant that the immediate delivery of the majority of acute medical care has been by doctors in training, with senior consultation. Despite this, there have always been physicians deeply interested in the management of medical emergencies, and educational events targeting this area are almost always over-subscribed. The direct involvement of consultant physicians in the process of the acute medical intake has increased over time, driven in part by the interest of some, but also the perceived inappropriateness by many, of the most seriously ill patients being managed for long periods of time by junior doctors without early consultant involvement. In many areas however, consultant physicians remained uninvolved in the immediate care and resuscitation of emergency admissions, and the quality of care of the acutely ill medical patient has been questioned in a number of forums, including the Journal of Accident and Emergency Medicine. ${ }^{3}$ In truth only the increased presence of appropriately trained consultant physicians at the front door of medicine could bring the quality change that was needed. From this background developed the subspecialty of acute medicine.

A key development was the introduction of dedicated areas for the reception of emergency medical admissions. Traditionally emergency medical admissions had been admitted to the ward of the physician on call, but with the inexoradmissions, ward based admissions were lost, with patients being admitted initially to any available medical bed, and later to virtually any bed in the able rise in the numbers of emergency hospital. The inefficiency of this process, with the admitting team spending almost as much time rushing from ward to ward as with their patients, had to be resolved. Medical admission units (MAUs) helped this resolution. MAUs however also provided a location for the practice of acute medicine, and those interested tended to gravitate towards them, while those not interested drifted away. This was true of both nursing and medical staff. There then evolved a number of new models of consultant involvement, starting with the duty consultant cancelling fixed commitments to do a formal post-take round, to cancelling commitments on part or all of the day of admission-physician of the day, to cancelling commitments for a prolonged period-physician of the week or part week. Ultimately came the development of the physician who had little or no inpatient bed holding other than on the MAU-the consultant physician in acute medicine.

Subsequently, Trusts have found particularly attractive the ability of consultant physicians in acute medicine to use ambulatory care to provide the "bed equivalents" described by Derek Wanless in The Review of Health and Social Care in Wales. ${ }^{4}$ This entails the care of patients as outpatients, with early and frequent review, who would previously have been managed as inpatients. Ambulatory care is clearly an important aspect of acute medicine, and has helped cope with the problem of lack of capacity to accommodate emergency medical admissions. This is, however, only one aspect of the discipline and improving the quality of care of patients admitted as medical emergencies is equally important. The consultant physician in acute medicine provides expertise in the best initial care; as good as that of the appropriate specialist, but limited to a maximum of the first 48 hours of care, by which time triage to the appropriate specialty should have taken place.

Acute medicine first caught the eye of the Royal Colleges in 1998 when the Scottish Colleges reported on The Future of General Medicine and Acute Medical Admissions. ${ }^{5}$ Subsequently a working party was set up by the Federation of Medical Royal Colleges, chaired by Professor Carol Black, to examine the role of the physician in acute medicine. ${ }^{6}$ This included representation from emergency medicine, both on the working party itself and among those giving evidence (Richard Hardern and Roger Evans) and reported in 2000. The conclusions of this working party seemed discouraging to those favouring the rapid development of acute medicine, 
but did not slow the increasing number of consultant and staff grade appointments being made to MAUs.

Many of the physicians who presented to the working party decided to meet again. The Royal College of Physicians facilitated this and the Acute Medicine Group was formed. This group met again in Edinburgh, and the Society for Acute Medicine was established. One of the first actions of the newly formed society was to sound out the attitudes of emergency medicine and critical care medicine to our ambitions. It fell to me to speak with friends and notaries in emergency medicine. The response at that time, some three years ago, was that many emergency physicians were pleased to see medicine taking a greater interest in acutely ill patients, some said not before time, and generally there was a feeling of goodwill. There was a smaller group, often of those with experience or knowledge of the American or Australasian style of emergency medicine, who had themselves similar ambitions to ours for the initial care of emergency medicine admissions. I suspect that the situation is similar today.

So who should provide the initial care for the acutely ill medical patient? I don't think that there is necessarily a single answer, for a number of reasons. Different hospitals will have consultant staff in both emergency and general medicine who have differing ambitions and enthusiasms for the early management of ill patients. Recent experience has shown that trusts are keen to recruit consultant physicians in acute medicine, but the early enthusiasts are all in post and the newly developed training schemes will not produce their first graduates for another three years, and even then the numbers will be few. It perhaps matters less who does the job than that it is done well. Best care will demand close working between all those involved and this will include practitioners of acute medicine, emergency medicine, and critical care medicine, who will need to develop uniform management strategies that are well founded, well disseminated, and used when any discipline is caring for similar patients. The Royal College of Physicians has recognised this and produced two reports $^{78}$ on the interface between acute medicine and the two specialties.

Recently the Royal College of Physicians reviewed its thoughts on acute medicine and its most latest report, Acute medicine: making it work for patients ${ }^{9}$ shows a substantial change in thinking, due in no small part to the efforts of Professor Black, now the President of the College and Dr George Cowan, Medical Director of the Joint Committee for Higher Medical Education (JCHMT). Rather than suggesting that consultant posts in acute medicine were undesirable, it now recommends a minimum of three such posts in every hospital by 2008. Moreover, throughout the document there is evidence of a change in philosophy regarding the organisation of care for the acutely ill medical patient, with emphasis on cooperation between acute medicine and emergency medicine. There are suggestions of consultant appointments in acute medicine having commitments to accident and emergency departments, high dependency units, and intensive care units. Perhaps most significantly there is a recommendation that "clear pathways are developed to facilitate higher specialist training in Acute Medicine for doctors with a background in Emergency (A\&E) Medicine and Critical Care, who have appropriate basic specialist training, but do not necessarily have the MRCP(UK) Diploma". ${ }^{7}$ While this is in keeping with the change in $\mathrm{G}(\mathrm{I}) \mathrm{M}$ training towards competency based standards, it does mark a significant departure from previous practice and it remains to be seen how practicable it is to determine equivalent competence and experience.

So the past few years have been an interesting time. If all works well I hope

\section{Changes and thanks}

\section{Jim Wardrope, Pete Driscoll}

\section{$E M J$ goes monthly and important changes in requirements for patient consent.}

$T^{\mathrm{n}}$ he EMJ will become a monthly publication in January 2005. This is a major step in the development

of the journal. We thank all those who have worked so hard to achieve this aim, especially the great support from we will all be winners, with specialist acute care and improved inter-departmental organisation resulting in the most important thing of all, a better experience and quality of care for our patients.

\section{ACKNOWLEDGEMENTS}

The assistance of Dr Michael C Jones, consultant physician in acute medicine, Ninewells Hospital and Medical School, Dundee; Vice President, The Society for Acute Medicine (UK) is acknowledged.

Emerg Med J 2004;21:652-653. doi: 10.1136/emj.2003.012211

Correspondence to: Dr J R Dowdle, Department of Medicine, Royal Glamorgan Hospital, Llantrisant, Rhondda-Cynon-Taf CF72 8XR, UK; rhid.dowdle@pr-tr.wales.nhs.uk

Funding: none

Competing interests: none declared.

The author is Secretary of The Society for Acute Medicine (UK).

\section{REFERENCES}

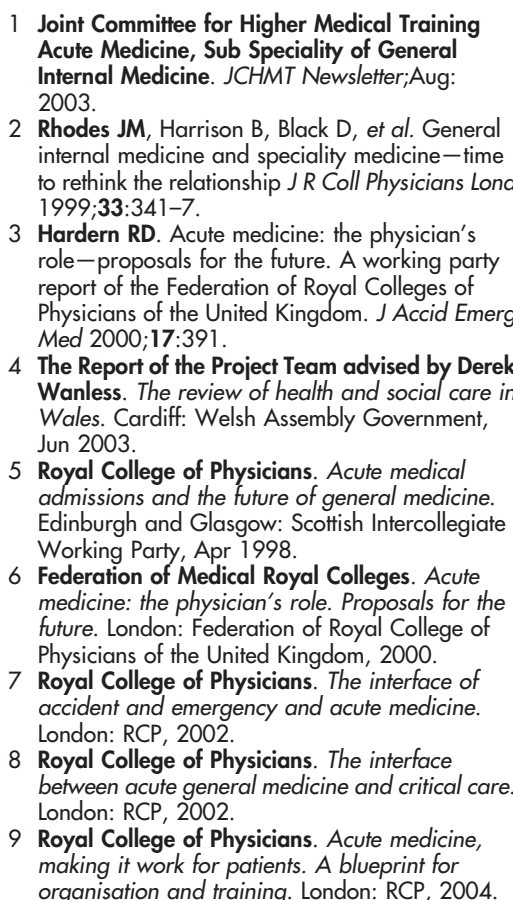
organisation and training. London: RCP, 2004.

the British Association for Emergency Medicine, the British Association for Immediate Care (BASICS), the Faculty of Pre-hospital Care, and BASICS Scotland. This change will allow us to be more topical, more reactive, and quicker at publishing accepted papers, a particularly worrying problem for the journal and authors.

In advance of this change we have reviewed our policies and procedures. These can be viewed in full on http://emj.bmjjournals.com/misc/ ifora/jnlguidelines.shtml. One significant change is that we now require patient consent for case reports or small 
case series where there is patient identifiable information. All other research requires ethical approval and we feel that this is important step in protecting patient privacy. There may be times when consent is not possible but these will be few in number. This change will apply to case reports submitted after l January 2005. A copy of a consent form can be obtained from http://emj. bmjjournals.com/misc/ifora/patconsent. shtml.

We have also updated the instructions for reviewers. A heartfelt thanks to all our reviewers who give time and brainpower freely to assist the journal. Your hard work is much appreciated (see page 717). We believe the quality of papers in the EMJ has significantly increased and the review process is part of this quality improvement.

If you do review for the EMJ could you read the new instructions for reviewers on http://emj.bmjjournals. com/misc/ifora/. The changes are not major but are in response to some ideas you have suggested.

Finally, we would like to thank Claire Jura for her work for the EMJ. For three years she has been the editorial assistant for the journal, the ever patient voice on the EMJ telephone and a great supporter of the editorial team. Recently she was promoted within the BMJ Group and has been replaced by Craig Raybould. We welcome Craig to the EMJ team.

Emerg Med J 2004;21:653-654.

doi: $10.1136 /$ emj.2004.020081

Authors' affiliations

Jim Wardrope, Pete Driscoll, Joint Editors

Correspondence to: emjeditorial@bmigroup. com

\section{Editor Emergency Medicine Journal}

Applications are invited for the post of Editor of the Emergency Medicine Journal. The journal is jointly owned and published by the British Association for Emergency Medicine and the BMJ Publishing Group Ltd.

We are seeking an Editor who can build on the journal's established strengths and make it ever more international and appealing to emergency care professionals. The journal aspires to be a "must read" in emergency care, and to achieve this academic research needs to be made relevant and accessible and the key messages emphasised.

Joint applications from two or more individuals willing to act as a team are welcomed, as are applications from outside the UK. Although previous editorial experience is not a strict requirement, it would be an advantage.

Full editorial support and training will be provided and it is envisaged that the Editor will need to devote the equivalent of 1 day per week to the journal.

Please send a letter of application, a curriculum vitae, a statement of the strengths and weaknesses of the journal, and a brief résume of your proposed editorial policy.

Closing date is Tuesday, 23 November 2004. Interviews will be held on Monday, 6 December 2004 at BMA House, London. It is envisaged that the outgoing editors will gradually hand over during the first half of 2005 and the successful candidate(s) will officially take up the post of Editor in May 2005.

Details of the post can be discussed with the current editors (Mr Jim Wardrope, email: jimwardrope@hotmail.com and Mr Peter Drìscoll, email: peter.driscoll@srht.nhs.uk) or Mrs Alex Williamson, to whom applications should be sent. $A$ job description is available on request.

Mrs Alex Williamson, BMJ Publishing Group.

BMA House, Tavistock Square,

London WC1H 9JR, UK.

Telephone: +44(0)20 73836169 .

Fax: +44(0)207383 6668 .

Email: awilliamson@bmjgroup.com

414356-1

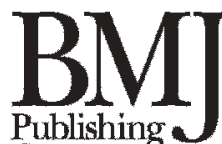

Group 